\title{
Explaining the obesity paradox in healthcare utilization among people with type 2 diabetes
}

\author{
Virender Kumar $^{1} \cdot$ William Encinosa ${ }^{1}[\mathbb{D}$
}

Received: 6 May 2021 / Accepted: 12 August 2021 / Published online: 7 September 2021

This is a U.S. government work and not under copyright protection in the U.S.; foreign copyright protection may apply 2021

\begin{abstract}
Background Several studies of diabetes suggest an obesity paradox: persons without diabetes have an increased risk of death due to obesity, whereas obesity decreases the risk of death for people with diabetes. A recent study finds the same obesity paradox with the number of healthcare visits. Whether empirical biases and confounding lead to this paradox is yet to be determined.

Objective To examine changes in the relationship between BMI and number of visits in diabetic vs nondiabetic populations, controlling for confounding risk factors.

Methods Using adults in the nationally representative Medical Expenditure Panel Survey (MEPS) from 2008 to 2016, $N=210,317$, we examine the proposed relationship using six measures of healthcare visits with zero-inflated negative binomial regressions controlling for age, gender, race/ethnicity, income, education, region, health insurance, chronic conditions, and smoking. We excluded persons with type 1 diabetes and gestational diabetes.

Results We find an obesity paradox among people with diabetes for three measures. That is, relative to people without diabetes, normal weight people with diabetes have more emergency room visits, inpatient, and office-based physician visits than do the obese with diabetes. However, we do not find an obesity paradox in any of the six measures once we exclude smokers and persons ever diagnosed with cancer or cardiovascular disease.

Conclusion The obesity paradox does not exist at the utilization level and is due to the presence of statistical biases such as confounding and reverse causation. Physicians should continue to focus on efforts to prevent obesity in patients with diabetes.
\end{abstract}

Keywords Obesity $\cdot$ Healthcare utilization $\cdot$ Diabetes $\cdot$ Outpatient visits

\section{Introduction}

Increases in body mass index (BMI) increase the risk of mortality [1-5] and the likelihood of developing type 2 diabetes and other diseases (e.g., cardiovascular disease, hypertension, coronary artery disease, stroke and heart failure) [6-12]. However, a number of studies[12-19] investigating individuals with type 2 diabetes have shown a decrease in mortality risk among overweight and obese individuals compared to normal weight people, a phenomenon called the "Obesity Paradox" $[20,21]$ Obesity accounts for $80-85$ percent of overall risk for type 2 diabetes [22]. Because of the obesity paradox, clinicians might place less emphasis

William Encinosa

william.encinosa@ahrq.hhs.gov

$1 \quad$ Agency for Healthcare Research and Quality and Georgetown University, Georgetown, USA on preventing obesity among patients with diabetes. This has recently become the focus of more scrutiny during the COVID-19 pandemic since both obesity and diabetes are high risk categories for COVID. In this paper, we reexamine the obesity paradox.

One explanation for the obesity paradox is the failure to address confounding variables and reverse causation biases in studies examining the relation between obesity and the risk of mortality [23]. For example, since smoking is negatively associated with BMI and positively associated with risk of mortality, appropriate analytical adjustment for the confounding effect of smoking status is important [24]. Some chronic diseases such as cancer lead to both weight loss and elevated risk of death [25-28], thus leading to an underestimation of the effect of weight on mortality risk. Another explanation for the paradox is that diabetes among non-obese persons may be the result of different and possibly more severe disease processes [13]. Some chronic 
diseases (e.g., cardiovascular diseases) can cause weight loss, more so among persons with diabetes, and are most likely to be positively associated with number of visits. In addition, if diabetes among non-obese people represents a more severe disease process, one can expect the presence of the obesity paradox in the number of visits among persons with diabetes.

To our knowledge, only one study has examined the existence of the obesity paradox in the use of emergency room and inpatient services among persons with diabetes using the Medical Expenditure Panel Survey (MEPS) data for the years 2000-2011 [29]. Among persons with diabetes, this study found that the use of one or more inpatient ( $\geq 1 \mathrm{vs}$ none) and emergency room ( $\geq 1$ vs none) services was 3.9 percentage points and 3.5 percentage points higher, respectively, among normal weight individuals than among the obese individuals. Our study builds on this study using the same data in the following ways. First, we update the data to 2008-2016. Second, we restrict our study to persons with type 2 diabetes excluding women with gestational diabetes and individuals with type 1 diabetes. Third, we examine a wider spectrum of visits (e.g., office-based, outpatient, emergency room, and inpatient visits). Fourth, we include additional provider settings (e.g. office-based total as well as physician visits, and outpatient all as well as outpatient physician visits). Fifth, we also analyze number of visits by excluding smokers and persons with cancer or cardiovascular disease diagnoses.

\section{Methods}

\section{Data sample}

The Medical Expenditure Panel Survey (MEPS) is an annual nationally representative survey sponsored by the Agency for Healthcare Research and Quality (AHRQ). A new panel is introduced every year and persons in each panel are followed for two years. Every year, the survey interviews about 15,000 households to get a nationally representative sample of the civilian, non-institutionalized US population. It collects health status, health insurance coverage, and health care number of visits and expenditures information for each household over the course of two years. This study uses MEPS data for the years 2008-2016. There were 210,797 persons (including 335 individuals identified as diabetic at the time of the Diabetes Supplement Survey but not in the regular household survey) with a positive survey weight as well as non-missing BMI. Our analytic sample included persons who were never diagnosed with diabetes or were diagnosed with type 2 diabetes by excluding those (a) who were taking only insulin and were below the age of 30 at the time of diagnosis $(n=469)$ and (b) those who reported being pregnant and were diagnosed with diabetes during the survey year $(n=11)$. There were 210,317 individuals in our analytical sample. For additional analyses, we excluded those with a history of smoking and those with a history of cancer or cardiovascular disease diagnoses (myocardial infarction, angina, coronary heart disease, stroke and other heart disease). The sample for additional analyses included 142,551 individuals. From this point onward, we will refer to the analytic sample as the ANS sample and the sample for additional analyses as the ADS sample.

\section{Measures}

\section{Health care number of visits}

We used the following visit measures:

All outpatient visits $(\geq 0)$. Total number of visits to hospital outpatient departments.

Outpatient visits to physicians $(\geq 0)$. Total number of hospital outpatient department visits to physicians.

All office-based provider visits $(\geq 0)$. Total number of visits to office-based (OBD) health care providers (physicians as well non-physicians).

Office-based physician visits $(\geq 0)$. Total number of office-based visits to physicians.

Emergency room visits $(\geq 0)$. Total number of visits to the emergency room (ER).

Inpatient stays $(\geq 0)$. Total number of hospital inpatient discharges.

\section{Health status and sociodemographics}

We used BMI $\left(\mathrm{kg} / \mathrm{m}^{2}\right)$ to categorize an individual's weight using five dummy variables - underweight (BMI $<20)$, normal weight $(20 \leq \mathrm{BMI}<25)$, overweight $(25 \leq \mathrm{BMI}<30)$, obese $(30 \leq \mathrm{BMI}<35)$, and severely obese $(35>\mathrm{BMI})$. Diabetes was self-reported either in the household survey or in the diabetes supplement survey. We used an individual's age in years and reported smoking status as a dummy variable.

An individual's health insurance status was indicated via dummy variables - any private (not with non-Medicare public insurance), Medicare only, any public (with/without Medicare or private) and uninsured. Private coverage indicated coverage by private third parties or Tricare. A five-category variable controlled for individuals' education in terms of years of education. Education categories were-post-graduate ( $>16 \mathrm{yrs})$, college graduate (16 yrs), some college (13-15 yrs), high school graduate (12 yrs) and less than high school ( $<12$ yrs). Other indicator variables included: seven self-reported chronic conditions (hypertension, asthma, stroke, emphysema, coronary heart disease, 
cancer, and myocardial infraction), gender, race/ethnicity (Asian, Hispanics, African-American and Non-Hispanic other races), household income level as a percentage of Federal Poverty Level ( $>=200 \%, 125 \%$ to $<200 \%, 100 \%$ to $<125 \%$ or $<100 \%$ ), and census region (West, Midwest, South, and Northeast). We accounted for year-specific fixed effects by using an indicator variable for each data year.

\section{Statistical analysis}

We examine whether obesity is associated with lower health care utilization (fewer outpatient (OP), office-based, emergency room, and inpatient visits) compared to normal weight patients, and whether this association varies among patients with diabetes compared to patients without diabetes. This study used Stata SE 15.1 (Stata Corporation, College Station, TX) to predict the risk adjusted number of visits. We used a generalized negative binomial regression model to risk adjust and predict visits to OP settings (all and physician only) and visits to OBD providers (all and physician only), and we used a zero-inflated negative binomial model to predict ER visits and inpatient stays. All models accounted for the MEPS complex survey design. The specified models had the lowest AIC and BIC values among the four models we tested-Poisson, negative binomial, generalized negative binomial, and zero-inflated negative binomial.

Our analyses examined changes in the association between BMI and each of the six health care number of visits measures with diabetes status. We used the Stata margin command to predict the marginal effect of each BMI category at sampled values of all other predictors on each type of health care number of visits. We examined the difference between the marginal number of visits for any two BMI categories. We also compared the difference between any two BMI categories among individuals with diabetes to the difference between the same two BMI categories among individuals without diabetes (we refer to this as the "difference-in-difference" estimate).

\section{Results}

Table 1 presents demographic characteristics of the ANS and ADS samples. In the ANS sample, there were 210,317 adults aged 18 years and older with positive person weights in the MEPS consolidated public use files for years 2008-2016. 21,532 were diagnosed with type 2 diabetes and the rest had no diabetes diagnosis history (see Table 1). Compared to persons with type 2 diabetes, persons with no diabetes diagnosis were younger, more likely to be male, non-Hispanic, have higher household incomes and education, have any private insurance (private or private with Medicare) or have no insurance, reside in the West, have BMIs that were overweight or lower, more likely to be smokers, and were less likely to be diagnosed with any of the seven chronic diseases. Those reporting no cancer or no cardiovascular disease, and who were not current smokers, had relatively lower number of visits for each of the six health care provider types. In both the samples, individuals with no diabetes history had lower number of visits of each provider type than those with diabetes.

Table 2 presents estimated average number of visits by diabetes status and BMI categories for each visit measure within the ANS and ADS samples. The estimated average number of visits was significant for persons in each BMI group for any given measure irrespective of diabetes status (with/without diabetes) in both samples $(p<0.05)$. Tables 3 and 4 present differences in the estimated number of visits within and between persons with and without diabetes for the ANS and ADS samples, respectively. For each provider type in both samples, ANS and ADS, the estimated average number of visits among individuals with diabetes was, in general, higher than that of persons without diabetes in each BMI group (see Tables 3 and 4). In the ANS sample, among persons without diabetes, the average number of visits increased with BMI among normal to higher weight groups for all measures (see Table 3 and Fig. 1a, 2a, 3a, $4 a, 5 a$ and $6 a$ ), where the mean number of visits in the normal weight group was significantly lower than that in the obese group for five visit measures [All OP (0.058 visits, $p<0.015)$; All OBD (0.565 visits, $p<0.001)$; OBD Physician (0.279 visits, $p<0.001)$; ER (0.027 visits, $p<0.001)$; Inpatient stays $(0.012$ stays, $p<0.007)$ ], and lower than the mean number of visits among the severely obese for all six measures [All OP ( 0.249 visits, $p<0.001)$; OP Physician (0.064 visits, $p<0.001)$; All OBD $(0.996$ visits, $p<0.001)$; OBD Physician (0.626 visits, $p<0.001)$; ER visits $(0.049$ visits, $p<0.001)$; Inpatient stays $(0.022$ stays, $p<0.001)$ ].

However, among persons with diabetes in Table 3, the mean number of visits in the normal weight group was higher than that in the overweight and obese groups for two measures (All OP visits and OBD physician visits), and higher than each of the three higher BMI groups for three measures (OP physician visits, ER visits, and inpatient stays). However, none of the visit differences between normal and higher weight groups among persons with diabetes, for any measure, were statistically significant at the 0.05 significance level. Conversely, the estimated number of visits to All OBD providers among normal to higher BMI individuals with diabetes increased with BMI.

The difference between those with and without diabetes in the number of visits difference between the normal weight and obese groups was significantly lower for three measures [OBD physicians $(-0.380$ visits, $p<0.046)$; ER $(-0.07$ visits, $p<0.003)$; inpatient $(-0.032$ stays, $p<0.025)$ ]. In addition, the difference between those with and without diabetes 
Table 1 Characteristics of the study sample

\begin{tabular}{|c|c|c|c|c|c|c|c|c|c|c|c|c|}
\hline \multirow{4}{*}{$\begin{array}{l}\text { Characteristics } \\
\text { Age, mean (SE) }\end{array}$} & \multicolumn{12}{|c|}{ Respondents (excluding persons with type 1 and gestational diabetes) } \\
\hline & & & & & & & $\begin{array}{l}\text { Exclu } \\
\text { disea }\end{array}$ & ling & oker & s, can & and $\mathrm{C}$ & $\mathrm{CVD}^{€}$ \\
\hline & \multicolumn{2}{|c|}{$\begin{array}{l}\text { All } \\
N=210,317\end{array}$} & \multicolumn{2}{|c|}{$\begin{array}{l}\text { With } \\
\text { diabetes } \\
N=21,532 \\
(10.2 \%)\end{array}$} & \multicolumn{2}{|c|}{$\begin{array}{l}\text { Without } \\
\text { diabetes } \\
N=188,785 \\
(89.8 \%)\end{array}$} & \multicolumn{2}{|c|}{$\begin{array}{l}\text { All } \\
N=12,551\end{array}$} & \multicolumn{2}{|c|}{$\begin{array}{l}\text { With } \\
\text { diabetes } \\
N=10,437 \\
(7.3 \%)\end{array}$} & \multicolumn{2}{|c|}{$\begin{array}{l}\text { Without } \\
\text { diabetes } \\
N=132,114 \\
(92.7 \%)\end{array}$} \\
\hline & 46.8 & $(0.2)$ & 61.6 & $(0.2)$ & 45.3 & $(0.18)$ & 42.8 & $(0.1)$ & 57.8 & $(0.2)$ & 41.7 & $(0.1)$ \\
\hline Female, \% (SE) & 51.4 & $(0.2)$ & 50.1 & $(0.6)$ & 51.6 & $(0.2)$ & 52.3 & $(0.2)$ & 51.4 & $(0.9)$ & 52.4 & $(0.2)$ \\
\hline \multicolumn{13}{|l|}{$\begin{array}{l}\text { Family income as \% } \\
\text { of } \mathrm{FPL}^{\alpha}, \% \text { (SE) }\end{array}$} \\
\hline$>=200 \%$ & 70.5 & $(0.5)$ & 63.1 & $(0.8)$ & 71.2 & $(0.5)$ & 73.7 & $(0.5)$ & 66.9 & $(0.9)$ & 74.1 & $(0.5)$ \\
\hline $125-<200 \%$ & 13.3 & $(0.2)$ & 16.4 & $(0.4)$ & 12.9 & $(0.2)$ & 12.3 & $(0.2)$ & 15.1 & $(0.5)$ & 12.1 & $(0.2)$ \\
\hline $100-<125 \%$ & 4.2 & $(0.1)$ & 6.0 & $(0.2)$ & 4.1 & $(0.1)$ & 3.7 & $(0.1)$ & 5.3 & $(0.3)$ & 3.5 & $(0.1)$ \\
\hline$<100 \%$ & 12.0 & $(0.3)$ & 14.5 & $(0.5)$ & 11.8 & $(0.3)$ & 10.4 & $(0.3)$ & 12.7 & $(0.6)$ & 10.2 & $(0.3)$ \\
\hline \multicolumn{13}{|l|}{ Education level, \% (SE) } \\
\hline $5+$ years college & 9.6 & $(0.3)$ & 6.5 & $(0.4)$ & 9.9 & $(0.3)$ & 10.5 & $(0.3)$ & 7.0 & $(0.6)$ & 10.8 & $(0.3)$ \\
\hline 4 years college & 15.8 & $(0.3)$ & 10.0 & $(0.4)$ & 16.4 & $(0.3)$ & 17.8 & $(0.3)$ & 11.3 & $(0.6)$ & 18.3 & $(0.3)$ \\
\hline Some college & 24.0 & $(0.2)$ & 22.2 & $(0.6)$ & 24.1 & $(0.2)$ & 24.0 & $(0.3)$ & 22.8 & $(0.8)$ & 24.0 & $(0.3)$ \\
\hline High school & 25.3 & $(0.3)$ & 29.8 & $(0.6)$ & 24.8 & $(0.2)$ & 22.6 & $(0.3)$ & 28.2 & $(0.8)$ & 22.2 & $(0.3)$ \\
\hline$<$ High school & 25.4 & $(0.3)$ & 31.6 & $(0.6)$ & 24.8 & $(0.3)$ & 25.1 & $(0.3)$ & 30.7 & $(0.7)$ & 24.7 & $(0.3)$ \\
\hline \multicolumn{13}{|l|}{ Race/ethnicity, \% (SE) } \\
\hline Other & 72.3 & $(0.8)$ & 68.7 & $(1.0)$ & 72.7 & $(0.8)$ & 67.8 & $(0.9)$ & 61.7 & $(1.2)$ & 68.2 & $(0.9)$ \\
\hline Hispanic & 12.9 & $(0.7)$ & 13.3 & $(0.9)$ & 12.9 & $(0.7)$ & 15.8 & $(0.8)$ & 17.1 & $(1.1)$ & 15.7 & $(0.8)$ \\
\hline Asian & 4.6 & $(0.4)$ & 4.3 & $(0.4)$ & 4.6 & $(0.4)$ & 5.9 & $(0.4)$ & 6.1 & $(0.6)$ & 5.9 & $(0.4)$ \\
\hline Black & 10.2 & $(0.5)$ & 13.7 & $(0.8)$ & 9.9 & $(0.5)$ & 10.5 & $(0.5)$ & 15.1 & $(0.9)$ & 10.2 & $(0.5)$ \\
\hline \multicolumn{13}{|c|}{ Health insurance ${ }^{\ddagger}, \%$ (SE) } \\
\hline Any private & 66.1 & $(0.5)$ & 55.4 & $(0.7)$ & 67.2 & $(0.6)$ & 70.3 & $(0.6)$ & 61.0 & $(0.9)$ & 71.0 & $(0.6)$ \\
\hline Medicare only & 7.4 & $(0.2)$ & 17.5 & $(0.4)$ & 6.4 & $(0.2)$ & 4.5 & $(0.1)$ & 12.5 & $(0.5)$ & 3.9 & $(0.1)$ \\
\hline Any public & 13.2 & $(0.4)$ & 19.9 & $(0.6))$ & 12.6 & $(0.4)$ & 11.4 & $(0.3)$ & 17.0 & $(0.7)$ & 11.0 & $(0.3)$ \\
\hline Uninsured & 13.2 & $(0.3)$ & 7.2 & $(0.3)$ & 13.8 & $(0.4)$ & 13.8 & $(0.4)$ & 9.4 & $(0.5)$ & 14.1 & $(0.4)$ \\
\hline \multicolumn{13}{|c|}{ Chronic conditions, \% (SE) } \\
\hline Hypertension & 32.9 & $(0.3)$ & 77.9 & $(0.5)$ & 28.3 & $(0.3)$ & 24.4 & $(0.3)$ & 71.1 & $(0.8)$ & 21.2 & $(0.3)$ \\
\hline Asthma & 9.4 & $(0.1)$ & 13.4 & $(0.4)$ & 9.0 & $(0.2)$ & 8.2 & $(0.2)$ & 10.1 & $(0.5)$ & 8.1 & $(0.2)$ \\
\hline Stroke & 3.7 & $(0.1)$ & 12.1 & $(0.4)$ & 2.8 & $(0.1)$ & - & - & - & - & - & - \\
\hline Emphysema & 2.2 & $(0.1)$ & 5.2 & $(0.3)$ & 1.9 & $(0.1)$ & 0.7 & $(0.0)$ & 1.7 & $(0.2)$ & 0.6 & $(0.0)$ \\
\hline $\mathrm{CHD}^{\epsilon}$ & 13.8 & $(0.2)$ & 32.7 & $(0.6)$ & 11.8 & $(0.2)$ & - & - & - & - & - & - \\
\hline $\mathrm{MI}^{€ \epsilon}$ & 3.7 & $(0.1)$ & 13.6 & $(0.4)$ & 2.7 & $(0.1)$ & - & - & - & - & - & - \\
\hline Cancer & 10.5 & $(0.2)$ & 18.9 & $(0.5)$ & 9.7 & $(0.2)$ & - & - & - & - & - & - \\
\hline Smoker, \% (SE) & 15.6 & $(0.3)$ & 13.8 & $(0.4)$ & 15.8 & $(0.3)$ & - & - & - & - & - & - \\
\hline \multicolumn{13}{|l|}{ Region } \\
\hline Northeast & 18.1 & $(0.6)$ & 17.2 & $(0.7)$ & 18.2 & $(0.6)$ & 18.4 & $(0.6)$ & 16.9 & $(0.7)$ & 18.5 & $(0.6)$ \\
\hline Midwest & 21.5 & $(0.6)$ & 21.4 & $(0.8)$ & 21.5 & $(0.6)$ & 20.3 & $(0.6)$ & 19.8 & $(0.9)$ & 20.3 & $(0.6)$ \\
\hline South & 37.1 & $(0.7)$ & 41.4 & $(1.0)$ & 36.6 & $(0.7)$ & 36.2 & $(0.8)$ & 41.4 & (1.1) & 35.9 & $(0.8)$ \\
\hline West & 23.3 & $(0.6)$ & 20.0 & $(0.8)$ & 21.5 & $(0.7)$ & 25.1 & $(0.7)$ & 22.0 & $(1.0)$ & 25.3 & $(0.7)$ \\
\hline \multicolumn{13}{|l|}{ BMI $\left(\mathrm{kg} / \mathrm{m}^{2}\right), \%(\mathrm{SE})$} \\
\hline$<20$, underweight & 5.5 & $(0.1)$ & 1.5 & $(0.1)$ & 5.9 & $(0.3)$ & 5.6 & $(0.1)$ & 1.0 & $(0.1)$ & 5.9 & $(0.1)$ \\
\hline $20-<25$, normal & 30.2 & $(0.3)$ & 12.6 & $(0.4)$ & 32.1 & $(0.3)$ & 31.3 & $(0.3)$ & 11.8 & $(0.5)$ & 32.7 & $(0.3)$ \\
\hline $25-<30$, overweight & 34.2 & $(0.2)$ & 30.3 & $(0.5)$ & 34.6 & $(0.2)$ & 34.1 & $(0.2)$ & 29.8 & $(0.7)$ & 34.4 & $(0.3)$ \\
\hline $30-<35$, obese & 17.9 & $(0.2)$ & 27.2 & $(0.5)$ & 16.9 & $(0.2)$ & 17.4 & $(0.2)$ & 28.4 & $(0.7)$ & 16.7 & $(0.2)$ \\
\hline
\end{tabular}


Table 1 (continued)

\begin{tabular}{|c|c|c|c|c|c|c|c|c|c|c|c|c|}
\hline \multirow{4}{*}{$\begin{array}{l}\text { Characteristics } \\
\begin{array}{l}>=35, \text { severely } \\
\text { obese }\end{array}\end{array}$} & \multicolumn{12}{|c|}{ Respondents (excluding persons with type 1 and gestational diabetes) } \\
\hline & \multirow{2}{*}{\multicolumn{2}{|c|}{$\begin{array}{l}\text { All } \\
N=210,317\end{array}$}} & \multirow{2}{*}{\multicolumn{2}{|c|}{$\begin{array}{l}\text { With } \\
\text { diabetes } \\
N=21,532 \\
(10.2 \%)\end{array}$}} & \multirow{2}{*}{\multicolumn{2}{|c|}{$\begin{array}{l}\text { Without } \\
\text { diabetes } \\
N=188,785 \\
(89.8 \%)\end{array}$}} & \multicolumn{6}{|c|}{$\begin{array}{l}\text { Excluding smokers, cancer and } \mathrm{CVD}^{\epsilon} \\
\text { disease }\end{array}$} \\
\hline & & & & & & & \multicolumn{2}{|c|}{$\begin{array}{l}\text { All } \\
N=12,551\end{array}$} & \multicolumn{2}{|c|}{$\begin{array}{l}\text { With } \\
\text { diabetes } \\
N=10,437 \\
(7.3 \%)\end{array}$} & \multicolumn{2}{|c|}{$\begin{array}{l}\text { Without } \\
\text { diabetes } \\
N=132,114 \\
(92.7 \%)\end{array}$} \\
\hline & 12.1 & $(0.2)$ & 28.5 & $(0.6)$ & 10.5 & $(0.2)$ & 11.5 & $(0.2)$ & 29.0 & $(0.7)$ & 10.3 & $(0.2)$ \\
\hline \multicolumn{13}{|c|}{ Healthcare use (visit/stay), mean (SE) } \\
\hline $\mathrm{OP}^{\kappa}:$ All visits ${ }^{\S}$ & 0.5 & $(0.02)$ & 1.1 & $(0.05)$ & 0.5 & $(0.01)$ & 0.3 & $(0.0)$ & 0.7 & $(0.0)$ & 0.3 & $(0.0)$ \\
\hline OP: Physician visits & 0.2 & $(0.01)$ & 0.5 & $(0.02)$ & 0.2 & (0.) & 0.1 & $(0.0)$ & 0.3 & $(0.0)$ & 0.1 & $(0.0)$ \\
\hline OBD $^{\kappa \kappa}:$ All visits ${ }^{\S \S}$ & 6.1 & $(0.07)$ & 10.8 & $(0.19)$ & 5.6 & $(0.07)$ & 4.7 & $(0.1)$ & 8.3 & $(0.2)$ & 4.4 & $(0.1)$ \\
\hline $\begin{array}{l}\text { OBD: Physician } \\
\text { visits }\end{array}$ & 3.6 & $(0.03)$ & 7.0 & $(0.11)$ & 3.2 & $(0.03)$ & 2.7 & $(0.0)$ & 5.3 & $(0.1)$ & 2.5 & $(0.0)$ \\
\hline $\mathrm{ER}^{\mathrm{\kappa \kappa \kappa}}$ visits & 0.2 & (0.) & 0.3 & $(0.01)$ & 0.2 & (0.) & 0.1 & $(0.0)$ & 0.2 & $(0.0)$ & 0.1 & $(0.0)$ \\
\hline Inpatient stays & 0.1 & (0.) & 0.2 & $(0.01)$ & 0.1 & (0.) & 0.1 & $(0.0)$ & 0.1 & $(0.0)$ & 0.1 & $(0.0)$ \\
\hline
\end{tabular}

${ }^{\alpha}$ Federal poverty level (FPL)

${ }^{¥}$ Any private includes any coverage through a private or tricare but not combined with non-Medicare public plan any time during the year; Any Public includes any coverage through non-Medicare public plans (e.g. Medicaid, SCHIP etc.); Medicare includes coverage through Medicare only; and Uninsured includes no-coverage throughout the year

${ }^{\S}$ Includes visits for laboratory tests and radiology services

$\S \S$ Includes visits to non-physician (e.g. chiropractor, psychologist, etc.)

${ }^{\mathrm{\kappa}} O P$ outpatient department

${ }^{\kappa \kappa} O B D$ office-based physicians

${ }^{\mathrm{k} \kappa \mathrm{K}} E R$ emergency room

${ }^{€} C V D$ cardiovascular disease

${ }^{€ €} \mathrm{CHD}$ coronary heart disease

$M I$ myocardial infarction

in the number of visit difference between the normal weight and severely obese groups was significantly lower for three measures [OP physicians $(-0.112$ visits, $p<0.020)$; OBD physicians $(-0.492$ visits, $p<0.020)$; ER $(-0.062$ visits, $p<0.040$ )]. Our results suggest the existence of the obesity paradox in four of the six measures. While the number of visits increased with BMI among normal to higher BMI groups for all visit measures in the group without diabetes, the number of visits in the normal weight group was higher than at least one greater BMI group among persons with diabetes for five measures. The only exception was All OBD providers, in which the number of visits increased with BMI among normal to higher BMI groups (See Fig. 3a).

In the ADS sample, for normal to higher weight persons without diabetes, the number of visits increased with BMI for each visit measure (see Table 4 and Fig. 2a, b). Relative to number of visits within the normal weight group, number of visits among severely obese individuals was higher and statistically significant for all measures [for each measure $p<0.001]$. In addition, compared to the number of visits among normal weight individuals, the number of visits among obese individuals was higher and statistically significant for five measures [all OP visits $(p<0.031)$; and all OBD visits, OBD physician visits, ER visits, and inpatient stays each had $p<0.001]$ and the number of visits among overweight individuals was higher and statistically significant for ER visits $(p<0.002)$, and weakly significant for inpatient stays $(p<0.052)$. Among normal to higher BMI persons with diabetes, number of visits increased with BMI for three measures (All OBD visits, OBD physician visits, and inpatient stays). For the remaining three measures, number of visits was lower among one or more greater BMI groups than the number of visits among the normal weight group. However, none of the differences in the number of visits between the normal weight group and each higher BMI group was statistically significant at the 0.05 significance level for any measure. Further, between those with diabetes and those without diabetes, the difference in number of visits between normal and each higher BMI group did not differ statistically at the 0.05 significance level for any given measure. This suggests that the obesity paradox does not exist once we exclude smokers and persons ever diagnosed with cancer or any cardiovascular disease. 
Table 2 Visits per person by health care setting and by BMI in persons with and without diabetes

\begin{tabular}{|c|c|c|c|c|c|c|c|c|c|c|c|c|c|}
\hline \multirow{3}{*}{\multicolumn{2}{|c|}{ BMI $\left(\mathrm{kg} / \mathrm{m}^{2}\right)$ category $^{\beta}$}} & \multicolumn{4}{|c|}{ Outpatient visits } & \multicolumn{4}{|c|}{ Office-based physician visits } & \multirow{2}{*}{\multicolumn{2}{|c|}{$\begin{array}{l}\begin{array}{l}\text { Emergency } \\
\text { room }\end{array} \\
\text { Visits }\end{array}$}} & \multirow{2}{*}{\multicolumn{2}{|c|}{$\begin{array}{l}\text { Inpatient } \\
\text { Stays }\end{array}$}} \\
\hline & & \multicolumn{2}{|l|}{$\mathrm{All}^{\S}$} & \multicolumn{2}{|c|}{ Physician } & \multicolumn{2}{|l|}{ All ${ }^{\S \S}$} & \multicolumn{2}{|c|}{ Physician } & & & & \\
\hline & & Mean & SE & Mean & SE & Mean & SE & Mean & SE & Mean & SE & Mean & SE \\
\hline \multicolumn{14}{|c|}{ All respondents (excluding persons with type 1 diabetes and women with gestational diabetes) } \\
\hline & & \multicolumn{12}{|c|}{ Average annual number of visits per person } \\
\hline \multirow[t]{5}{*}{ With diabetes } & Underweight & 0.850 & 0.311 & 0.393 & 0.168 & 7.338 & 0.743 & 4.930 & 0.529 & 0.326 & 0.060 & 0.260 & 0.034 \\
\hline & Normal & 0.748 & 0.072 & 0.378 & 0.048 & 8.098 & 0.339 & 5.126 & 0.183 & 0.282 & 0.022 & 0.151 & 0.013 \\
\hline & Overweight & 0.718 & 0.054 & 0.347 & 0.041 & 8.208 & 0.258 & 4.952 & 0.121 & 0.247 & 0.013 & 0.128 & 0.007 \\
\hline & Obese & 0.732 & 0.050 & 0.312 & 0.029 & 8.323 & 0.228 & 5.025 & 0.128 & 0.238 & 0.014 & 0.130 & 0.007 \\
\hline & Severely obese & 0.907 & 0.058 & 0.329 & 0.026 & 8.612 & 0.246 & 5.259 & 0.123 & 0.268 & 0.014 & 0.143 & 0.008 \\
\hline \multirow[t]{5}{*}{ Without diabetes } & Underweight & 0.462 & 0.032 & 0.201 & 0.017 & 5.440 & 0.158 & 3.267 & 0.078 & 0.199 & 0.009 & 0.106 & 0.005 \\
\hline & Normal & 0.459 & 0.015 & 0.193 & 0.007 & 5.563 & 0.095 & 3.285 & 0.048 & 0.178 & 0.004 & 0.091 & 0.003 \\
\hline & Overweight & 0.483 & 0.018 & 0.196 & 0.006 & 5.752 & 0.085 & 3.339 & 0.039 & 0.184 & 0.004 & 0.096 & 0.003 \\
\hline & Obese & 0.518 & 0.024 & 0.207 & 0.010 & 6.128 & 0.115 & 3.564 & 0.053 & 0.206 & 0.005 & 0.103 & 0.003 \\
\hline & Severely obese & 0.709 & 0.045 & 0.257 & 0.012 & 6.559 & 0.132 & 3.911 & 0.064 & 0.227 & 0.005 & 0.113 & 0.004 \\
\hline \multicolumn{14}{|c|}{ Respondents (further excluding smokers, with cancer and cardiovascular diseases) } \\
\hline & & \multicolumn{12}{|c|}{ Average annual number of visits per person } \\
\hline \multirow[t]{5}{*}{ With diabetes } & Under & 0.251 & 0.090 & 0.095 & 0.037 & 4.260 & 0.595 & 3.152 & 0.414 & 0.227 & 0.085 & 0.153 & 0.061 \\
\hline & Normal & 0.511 & 0.072 & 0.268 & 0.044 & 6.536 & 0.475 & 4.047 & 0.229 & 0.208 & 0.030 & 0.083 & 0.014 \\
\hline & Overweight & 0.471 & 0.062 & 0.239 & 0.045 & 6.752 & 0.346 & 4.075 & 0.174 & 0.191 & 0.021 & 0.089 & 0.009 \\
\hline & Obese & 0.548 & 0.053 & 0.220 & 0.026 & 6.827 & 0.282 & 4.236 & 0.179 & 0.198 & 0.026 & 0.089 & 0.009 \\
\hline & Severely obese & 0.664 & 0.065 & 0.239 & 0.026 & 7.106 & 0.291 & 4.307 & 0.157 & 0.224 & 0.017 & 0.098 & 0.009 \\
\hline \multirow[t]{5}{*}{ Without diabetes } & Underweight & 0.270 & 0.023 & 0.136 & 0.016 & 4.120 & 0.133 & 2.332 & 0.068 & 0.127 & 0.007 & 0.057 & 0.005 \\
\hline & Normal & 0.283 & 0.013 & 0.124 & 0.004 & 4.351 & 0.083 & 2.438 & 0.037 & 0.114 & 0.003 & 0.054 & 0.002 \\
\hline & Overweight & 0.310 & 0.014 & 0.130 & 0.005 & 4.473 & 0.069 & 2.497 & 0.031 & 0.128 & 0.003 & 0.059 & 0.002 \\
\hline & Obese & 0.326 & 0.020 & 0.125 & 0.006 & 4.797 & 0.110 & 2.662 & 0.048 & 0.145 & 0.004 & 0.066 & 0.003 \\
\hline & Severely obese & 0.402 & 0.024 & 0.163 & 0.010 & 5.025 & 0.119 & 2.919 & 0.059 & 0.165 & 0.006 & 0.070 & 0.003 \\
\hline
\end{tabular}

${ }^{\beta} \mathrm{BMI}<20$ underweight, $20-<25$ normal, $25-<30$ overweight, $30-<35$ obese and $>=35$ severely obese

${ }^{\S}$ Includes visits for laboratory tests and radiology services

${ }^{\S}$ Includes visits to non-physician (e.g. chiropractor, psychologist, etc.)

\section{Discussion}

Using a nationally representative sample of non-institutionalized individuals, we analyzed health care number of visits for six provider types (All outpatient department, outpatient department physicians, all office-based-providers, officebased-physicians, emergency rooms, and inpatient stays) for individuals with and without type 2 diabetes. Our results suggest the existence of the obesity paradox in four (OP physicians, OBD physicians, ER, and inpatient stays) of the six measures. While number of visits increased with BMI among normal to higher BMI groups for all visit measures in the group without diabetes, and the difference between normal and at least one higher BMI group was statistically significant $(p<0.05)$, the number of visits among normal weight was higher than at least one of the higher BMI groups though not statistically different in the group with diabetes. The difference-in-difference test results suggest that the difference in number of visits between obese and normal weight individuals in the diabetes group was lower than the difference between the respective groups in the group without diabetes for three provider measures (OBD physicians, $\mathrm{ER}$, and inpatient stays). The difference in number of visits between the severely obese and normal weight categories in the diabetes group was lower than the difference in the same two groups in the group without diabetes for three measures (OP physicians, OBD physicians, and ER). These six difference-in-difference visit estimates were statistically significant at the 0.05 significance level, and thus, proved the presence of the obesity paradox. However, we did not find evidence of the obesity paradox in the number of visits of any of the six providers when we excluded smokers and individuals ever diagnosed with cancer or any cardiovascular disease from our sample of individuals with type 2 diabetes. Obesity contributes directly to the incidence of cardiovascular risk factors, and it also leads to the development of 


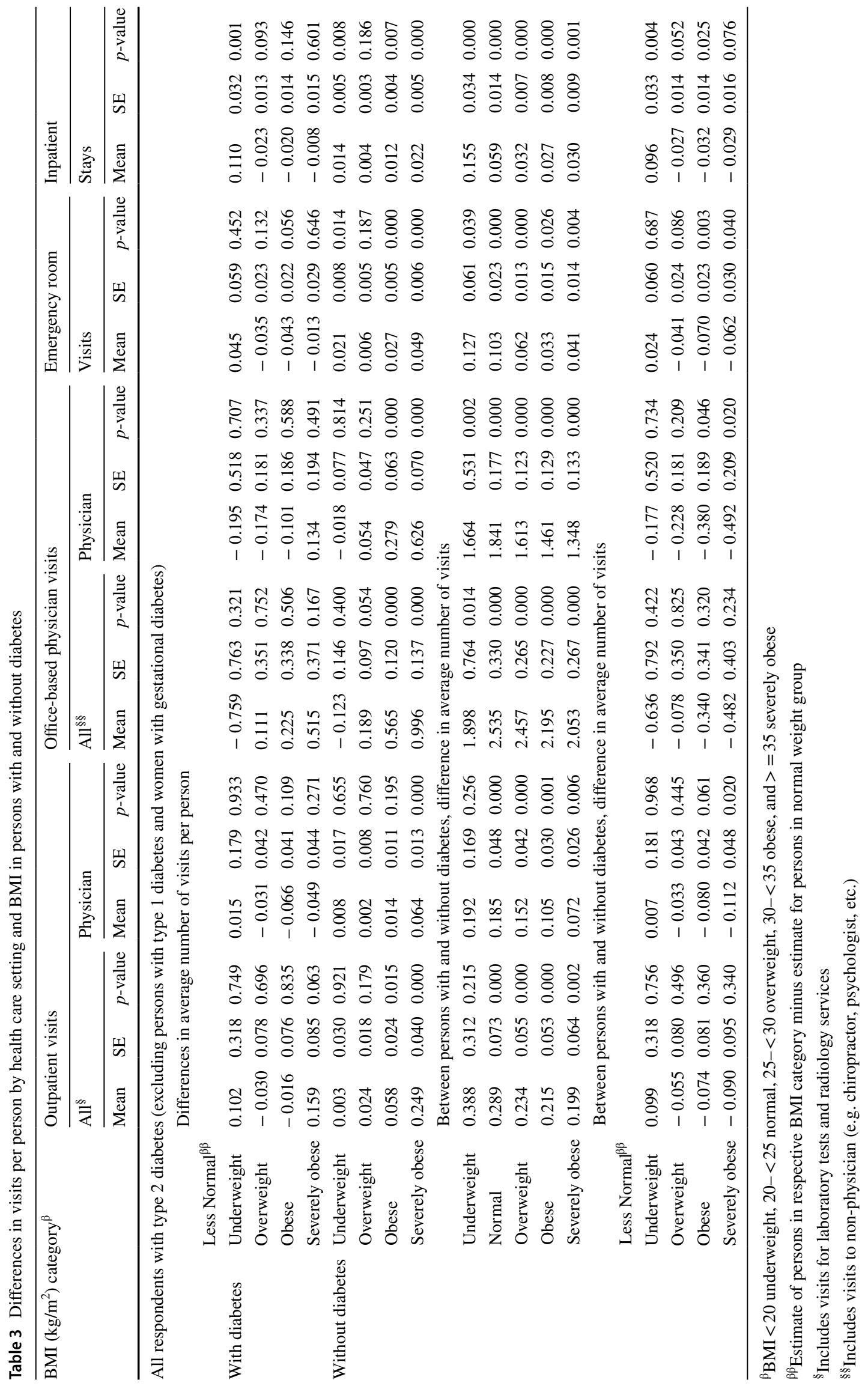




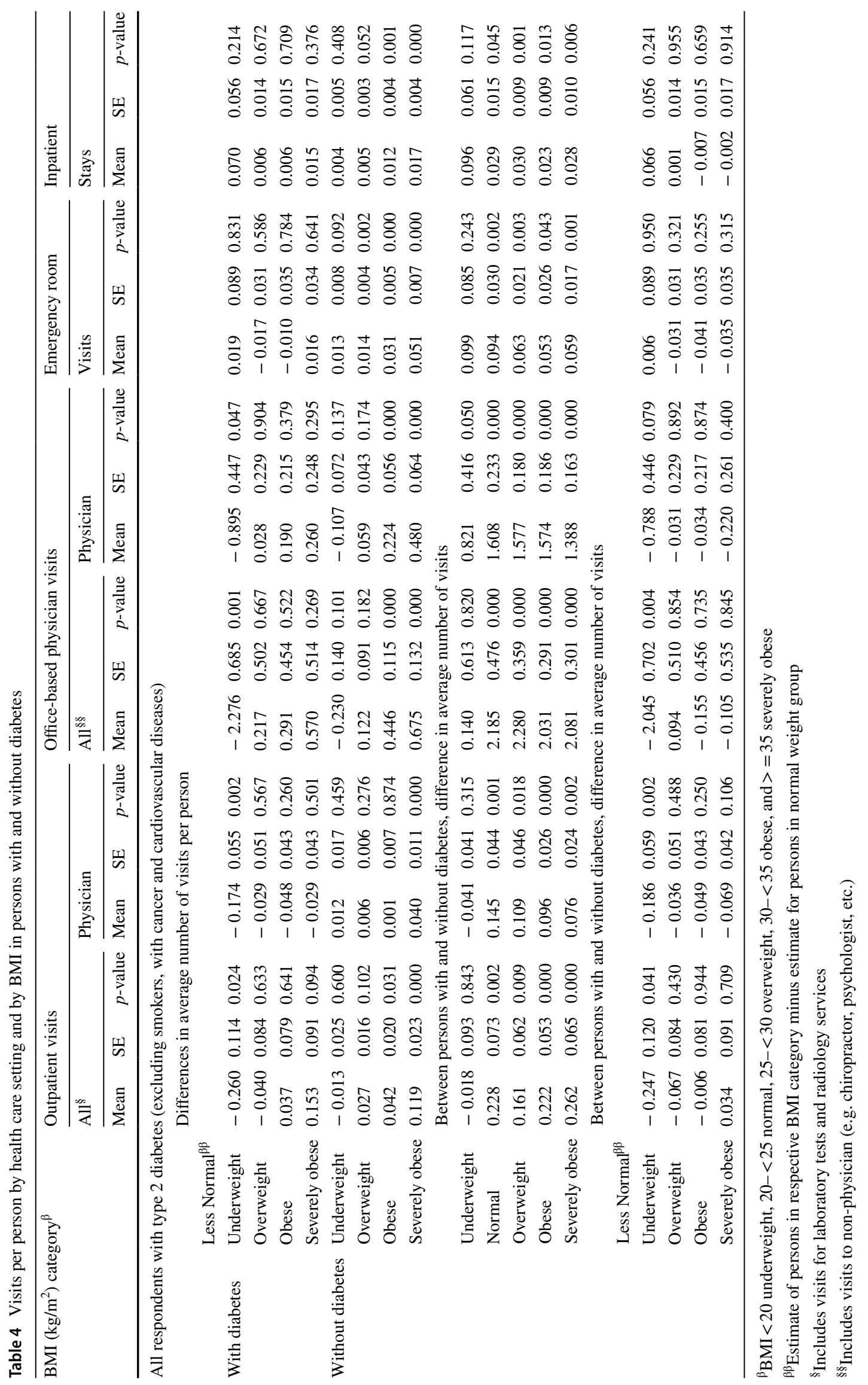


a

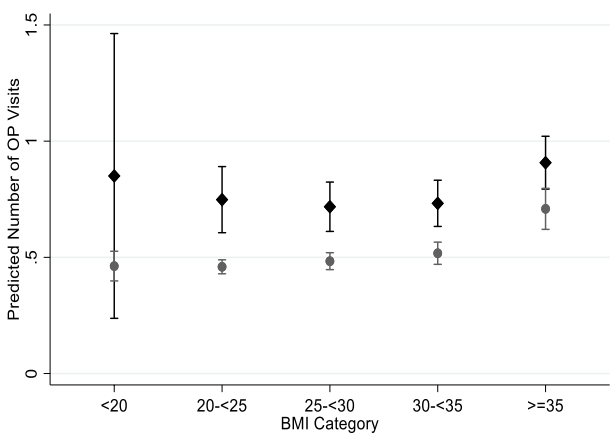

Fig. 1 Adjusted total utilization of all outpatient visits by BMI a is utilization for the analytical sample and $\mathbf{b}$ is for the sub sample in which ever-smokers and individuals with ever any diagnosis of cancer or any cardiovascular disease are excluded. Dark diamonds: point b

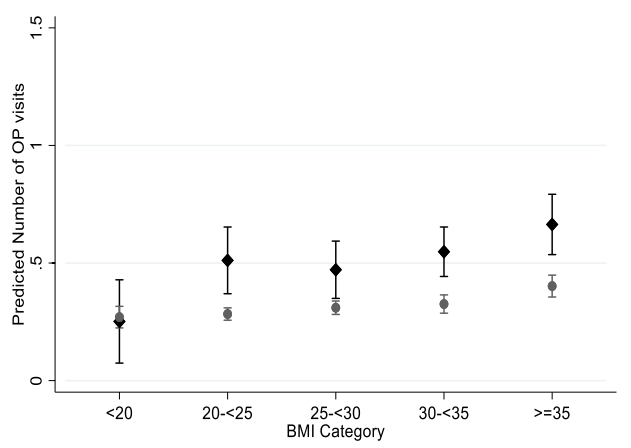

estimates for person with diabetes; light circles: point estimates for persons without diabetes; bars around point estimates indicate $95 \%$ confidence intervals. BMI indicates body mass index
Fig. 2 Adjusted total utilization of all outpatient physician visits by BMI $\mathbf{a}$ is utilization for the analytical sample and $\mathbf{b}$ is for the subsample in which eversmokers and individuals with ever any diagnosis of cancer or any cardiovascular disease are excluded. Dark diamonds: point estimates for person with diabetes; light circles: point estimates for persons without diabetes; bars around point estimates indicate $95 \%$ confidence intervals. BMI indicates body mass index

Fig. 3 Adjusted total utilization of all office-based physician visits by BMI. $\mathbf{a}$ is utilization for the analytical sample and $\mathbf{b}$ is for the subsample in which eversmokers and individuals with ever any diagnosis of cancer or any cardiovascular disease are excluded. Dark diamonds: point estimates for person with diabetes; light circles: point estimates for persons without diabetes; bars around point estimates indicate $95 \%$ confidence intervals. BMI indicates body mass index a

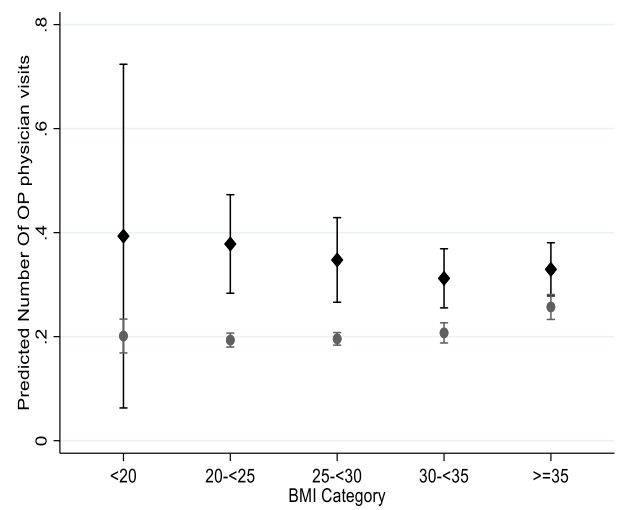

a

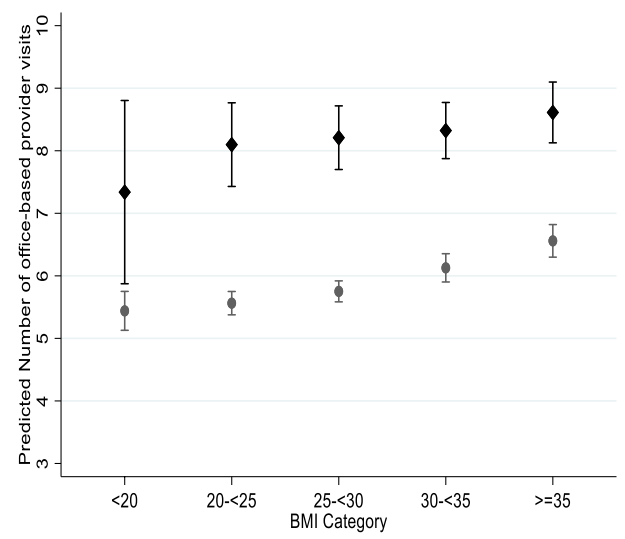

b

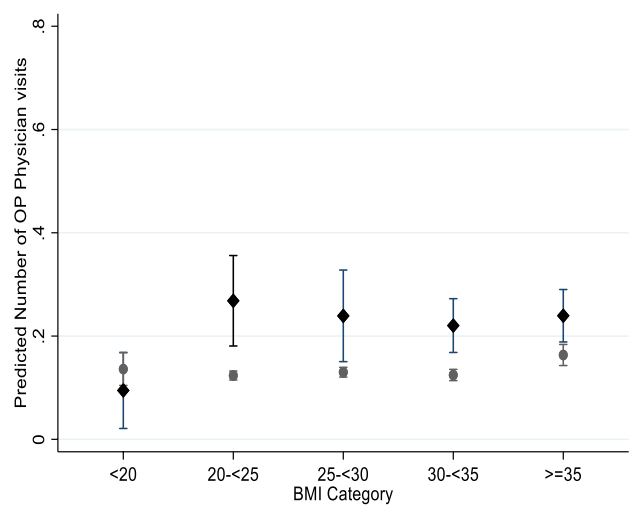

b

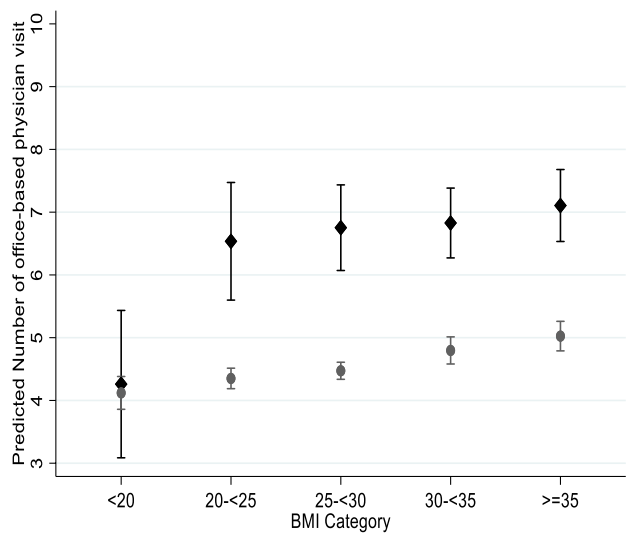

cardiovascular disease (CVD) [30]. Individuals with diabetes have a twofold to fourfold higher risk of CVD compared with those without diabetes [31]. Individuals suffering from cancer, chronic heart disease, chronic obstructive pulmonary disease, sepsis, and many other conditions experience involuntary weight loss and loss of muscle mass [28]. CVD is a major contributor to healthcare utilization and expenditures, particularly among older adults [32]. Our results suggest 
Fig. 4 Adjusted total utilization of all office-based physician visits by BMI. $\mathbf{a}$ is utilization for the analytical sample and $\mathbf{b}$ is for the subsample in which eversmokers and individuals with ever any diagnosis of cancer or any cardiovascular disease are excluded. Dark diamonds: point estimates for person with diabetes; light circles: point estimates for persons without diabetes; bars around point estimates indicate $95 \%$ confidence intervals. BMI indicates body mass index. a
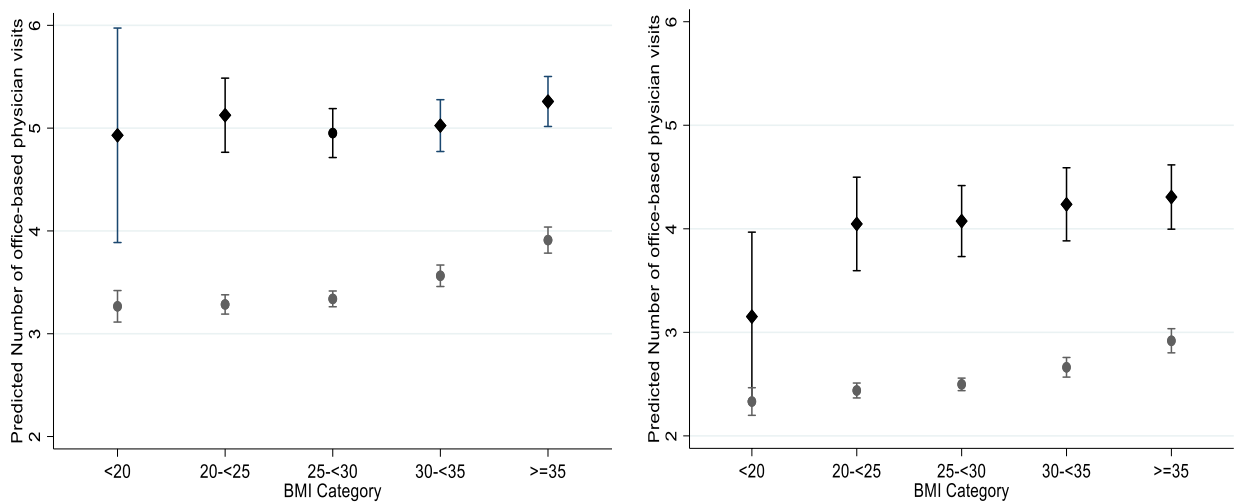

Fig. 5 Adjusted total utilization of all emergency department (ED) visits by BMI. a is utilization for the analytical sample and $\mathbf{b}$ is for the subsample in which ever-smokers and individuals with ever any diagnosis of cancer or any cardiovascular disease are excluded. Dark diamonds: point estimates for person with diabetes; light circles: point estimates for persons without diabetes; bars around point estimates indicate $95 \%$ confidence intervals. BMI indicates body mass index.

Fig. 6 Adjusted total utilization of all inpatient visits by BMI a is utilization for the analytical sample and $\mathbf{b}$ is for the subsample in which ever-smokers and individuals with ever any diagnosis of cancer or any cardiovascular disease are excluded. Dark diamonds: point estimates for person with diabetes; light circles: point estimates for persons without diabetes; bars around point estimates indicate $95 \%$ confidence intervals. BMI indicates body mass index. a
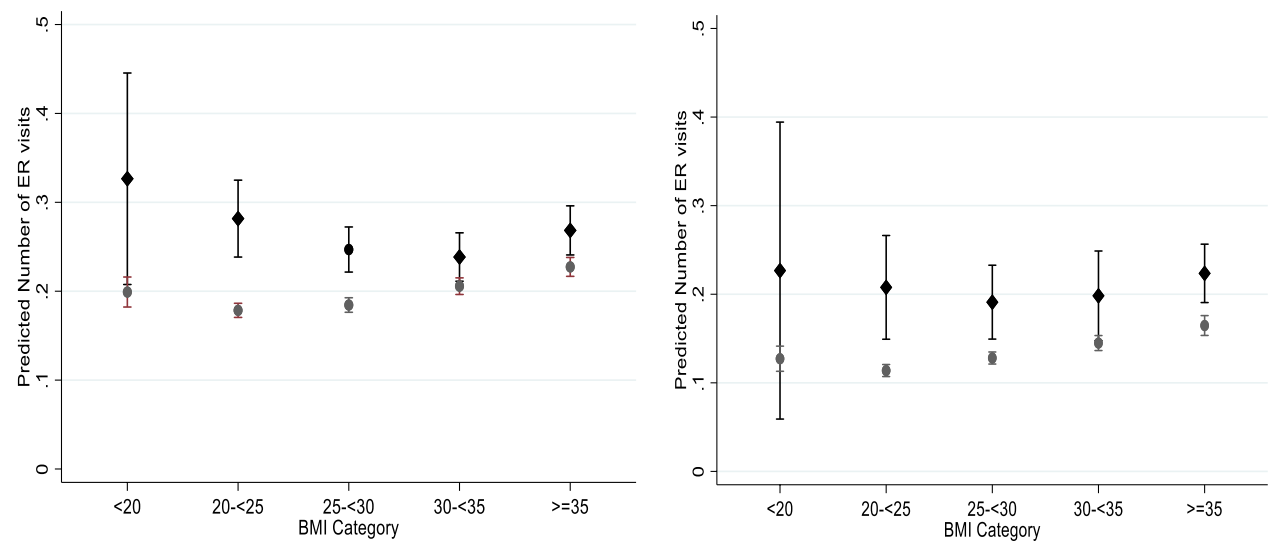

a

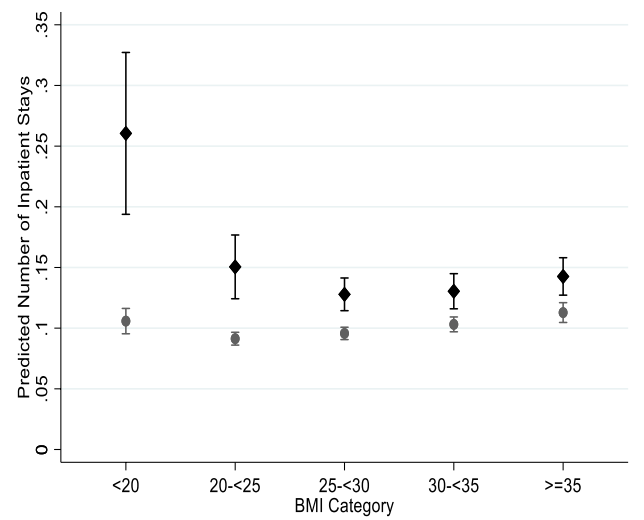

b

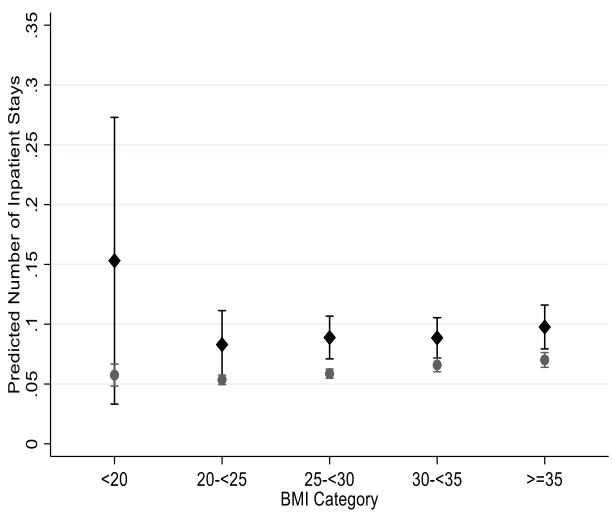

that two biases, residual confounding and reverse causation (collider bias), potentially account for the obesity paradox among individuals with type 2 diabetes [33].

Only one prior study has examined health care utilization ( $\geq 1$ visits vs none) by BMI category among individuals with and without diabetes, and it found that the overweight diabetic group had a significantly lower likelihood of having any inpatient stay or any emergency room visit than did the normal weight diabetic group but that these differences did not hold within the non-diabetic group [29]. However, the study included smokers, and individuals with type 1 gestational diabetes, or a history of cancer/cardiovascular disease 
diagnoses. In our study, we excluded individuals with type 1 or gestational diabetes in our main analytical sample (ANS). In addition, we designated as persons with diabetes those respondents who reported a diabetes diagnosis in the "Diabetes Supplement Survey" but did not report a diabetes diagnosis in the main MEPS survey. Further, we included interactions between age and diabetes status to account for differences in association between utilization (number of visits) and diabetes status as the person ages and to account for the changes in utilization (visits) with the duration of diabetes. In the additional analytical sample (ADS), we also excluded ever smokers, and those who were ever diagnosed with cancer or any kind of cardiovascular disease. Further, we analyzed total number of visits $(\geq 0)$ and not none $(=0)$ versus any $(>0)$ number of visits of four provider settings (outpatient, inpatient, emergency room, and office-based), as well as use of physician services in two settings (office-based and outpatient). In contrast, the previous study restricted analyses to any use of inpatient or emergency room services. In addition, we believe confounding effects due to the sequelae of chronic disease, cancer, and smoking status on an individual's BMI and health care use gave rise to the obesity paradox examined in the previous study. In addition, we believe individuals with type 1 diabetes vary immensely from individuals with type 2 diabetes, therefore, studies analyzing healthcare use among those with type 2 diabetes need to exclude those with type 1 diabetes. Further, we believe that women with gestational diabetes have a low risk of developing type 2 diabetes immediately after pregnancy and less than half of them are at risk of developing type 2 diabetes a few years after the current pregnancy. However, over the course of their pregnancy, these women will gain weight with little increase in healthcare utilization. Therefore, this group contributes to lower utilization within the higher BMI groups.

Our study has some limitations. First, this study used selfreported information. Therefore, it might have a reporting bias. For example, some respondents reported a diabetes diagnosis in the 'Diabetes Supplement Survey' but not in the main MEPS survey. However, accuracy of self-reported diabetes status has been shown to be reasonably high [34]. This study is cross-sectional, and, therefore, findings of this study cannot be interpreted as causal. This study used BMI as measure of obesity that has its own limitation as a measure of obesity [35]. Use of BMI is susceptible to biases, at least for the diabetic population's health utilization outcomes. However, we think that our study took care of many of the BMI limitations by excluding smokers, and persons with cancer, type 1 diabetes, cardiovascular diseases and gestation diabetes from the final sample, and that remaining limitations, if any, have minimal effect on our findings. Waist circumference has been found to be a better predictor of obesity [36]. Also, obesity paradoxes for all-cause mortality and kidney complications found under a BMI measure disappeared when waist circumference was used instead [37]. In the study, the obesity paradox increases with cardiovascular risk under the use of BMI. Our results further support this by showing that many biases with BMI are eliminated by removing the high risk cardiovascular cohort. Future studies may want to use the waist circumference measure to study the obesity paradox in utilization among persons with diabetes.

Acknowledgements The views expressed in this article are those of the authors, and no official endorsement by the U.S. Department of Health and Human Services, or the Agency for Healthcare Research and Quality (AHRQ) is intended or should be inferred. Funded by AHRQ. No conflicts of interest.

\section{Declarations}

Conflict of interests No conflict of interests.

Human rights and animal studies This study does not involve human subjects as determined by the Chesapeake Institutional Review Board's protocol, "Secondary Analysis of Confidential Data from the Medical Expenditure Panel Survey."

\section{References}

1. Adams KF, Schatzkin A, Harris TB, Harris TB, Kipnis V, Mouw T, Ballard-Barbash R, Hollenbeck A, Leitzmann MF. Overweight, obesity and mortality in a large prospective cohort of persons 50 to 71 years old. N Engl J Med. 2006;355:763-78.

2. Mulnier JE, Seaam JE, Raleigh VS, Soedamah-Muthu SS, Colhoun HM, Lawrenson RA. Mortality in people with type 2 diabetes in the UK. Diabet Med. 2006;23(5):516-21.

3. Eeggolofsson K, Cedeholm J, Nilsson PM, Zethelius B, Nunez L, Gudbjornsdottir S, Eliasson B. Risk of cardiovascular disease and mortality in overweight and obese patients with type 2 diabetes: an observational study in 13,087 patients. Diabetologia. 2009;52:66-73.

4. Berrington De Gonzalez A, Hartge P, Cerhan JR, Flint AJ, Hannan L, Maclnnis RJ, Moore SC, Tobias GS, Anton-Culver H, Freeman LB, Beeson WL, Clipp SL, et al. Body-mass index and mortality among 1.46 million white adults. $\mathrm{N}$ Engl J Mede. 2010;363:2211-9.

5. Zheng W, Mclerran DF, Rolland B, Zhang X, Inoue M, Matsuo K, He J, Gupta PC, Ramadas K, Tsugane S, Irie F,Akiko TamaKoshi, , et al. N Engl J Med. 2011;364:719-29.

6. Calle EE, Thun MJ, Petrelli JM, Rodriguez C. Body-mass index and mortality in a prospective cohort of U.S. adults. N Engl J Med. 1999;341(15):1097-105.

7. Diehr P, Bild DE, Harris TB, Duxbury A, Siscovick D, Rossi M. Body mass index and mortality in nonsmoking older adults: the cardiovascular health study. Am J Public Health. 1998;88(4):623-9.

8. Peeters A, Barendregt JJ, Willekens F, Mackenbach JP, Al Mamun A, Bonneux L. NEDCOM, the Netherland epidemiology and demography compression of morbidity research group. Ann Int Med. 2003;138(1):24-32. 
9. Kenchaiah S, Evans JC, Levy D, Wilson PWF, Benjamin EJ, Larson MG, Kannel WB, Vasan RS. Obesity and the risk of heart failure. N Engl J Med. 2002;347(5):305-13.

10. Dunlap SH, Sueta CA, Tomasko L, Adams KF Jr. Association of body mass, gender, and race with heart failure primarily due to hypertension. J Am Coll Cardiol. 1999;34(5):1602-8.

11. Katzmarzyk PT, Janssen I, Ardern CI. Physical inactivity, excess adiposity and premature mortality. Obes Rev. 2003;4(4):257-90.

12. Costanzo P, Cleland JGF, Pellicori P, Clark AL, Hepburn D, Kilpatrick ES, Perrone-Filardi P, Zhang J, Atkin SL. The obesity paradox in type 2 diabetes mellitus: relationship of body mass index to prognosis. Ann Intern Med. 2015;162:610-8.

13. Carnethon MR, De Chavez PJ, Biggs ML, Lewis CE, Pankow JS, Bertoni AG, Golden SH, Liu K, Mukamal KJ, Campbell-Jenkins B, Dyer AR. Association of weight status with mortality in adults with incident diabetes. JAMA. 2012;308(6):581-90.

14. Khalangot M, Tronko M, Kravchenko V, Kulchinska J, Hu G. Body mass index and the risk of total and cardiovascular mortality among patients with type 2 diabetes: a large prospective study in Ukraine. Heart. 2009;95(6):454-60.

15. Lajous M, Bijon A, Fagherazzi G, Boutron-Ruault MC, Balkau B, Clavel-Chapelon F, Hernan MA. Epidemiology. 2014;25(1):10-4.

16. Logue J, Walker JJ, Leese G, Lindsay R, McKnight J, Morris A, Philip S, Wild S, Sattar N. Scottish diabetes research network epidemiology group. Diabetes Care. 2013;36(4):887-93.

17. Thomas G, Khunti K, Curcin V, Molokhia M, Millett C, Majeed A, Paul S. Obesity paradox in people newly diagnosed with type 2 diabetes with and without prior cardiovascular disease. Diabetes Obes Metab. 2014;16:317-25.

18. Zhao W, Katzmarzyk PT, Horswell R, Wang Y, Li W, Johnson J, Heymsfield SB, Cefalu WT, Ryan DH, Hu G. Body mass index and the risk of all-cause mortality among patients with type 2 diabetes mellitus. Circulation. 2014;130(24):2143-51.

19. McEwen LN, Karter AJ, Waitzfelder BE, Crosson JC, Marrero DG, Manqione CM, Herman WH. Predictors of mortality over 8 years in type 2 diabetic patients: translating research into action for diabetes. Diabetes Care. 2012;35:1301-9.

20. Hainer V, Aldhoon-Hainerova I. Obesity paradox does exist. Diabetes Care. 2013;36(suppl 2):S276-81.

21. Standl E, Erbach M, Schnell O. Defending the con side: obesity paradox does not exist. Diabetes Care. 2013;36(suppl 2):S282-6.

22. Hauner H, et al. Obesity and diabetes. In: Holt RIG, Cockram CS, Flyvbjerg A, et al., editors. Textbook of diabetes. 4th ed. Oxford: Wiley-Blackwell; 2010.

23. Preston $\mathrm{SH}$, Stokes A. Obesity paradox conditioning on disease enhances biases in estimating the mortality risks of obesity. Epidemiology. 2014;25(3):454-61.

24. Manson JE, Stampfer MJ, Hennekens CH, Willett WC. Body weight and longevity: a reassessment. JAMA. 1987;257:353-8.

25. Tobias DK, Pan A, Jackson CL, O'Reilly EJ, Ding EL, Willett WC, Manson JE, Hu FB. Body-mass index and mortality among adults with incident type 2 diabetes. N Engl J Med. 2014;370:233-44.
26. Habbu A, Lakkis NM, Dokainish H. The obesity paradox: fact or fiction? Am J Cardiol. 2006;98:944-8.

27. Braun TP, Zhu X, Szumowski M, Scott GD, Grossberg AJ, Levasseur PR, Graham K, Khan S, Damaraju S, Colmers WF, Baracos VE, Marks DL. Central nervous system inflammation induces muscle atrophy via activation of the hypothalamic-pituitaryadrenal axis. J Exp Med. 2011;208:2449-63.

28. Morley JE, Thomas DR, Wilson MM. Cachexia: pathophysiology and clinical relevance. Am J Clin Nutr. 2006;83:735-43.

29. Jerant A, Bertakis KD, Franks P. Body mass index and health care Utilization in diabetic and nondiabetic individuals. Med Care. 2015;53(5):409-16.

30. Powell-Wiley TM, Poirier P, Burke LE, Després J, GordonLarsen P, Lavie CJ, Lear SA, Ndumele CE, Neeland IJ, Sanders $\mathrm{P}$, St-Onge M. and On behalf of the American Heart Association Council on Lifestyle and Cardiometabolic Health; Council on Cardiovascular and Stroke Nursing; Council on Clinical Cardiology; Council on Epidemiology and Prevention; and Stroke Council. Obesity and Cardiovascular Disease: A Scientific Statement From the American Heart Association. Circulation. 2021;143(21):e984 1010. https://doi.org/10.1161/CIR.0000000000000973.

31. Fox CS, Coady S, Sorlie PD, Levy D, Meigs JB, D'Agostino RB $\mathrm{Sr}$, Wilson PW, Savage PJ. Trends in cardiovascular complications of diabetes. JAMA. 2004;292:2495-9.

32. Odden MC, Coxson PG, Moran A, Lightwood JM, Goldman L, Bibbins-Domingo K. The impact of the aging population on coronary heart disease in the United States. Am J Med. 2011;124:827833.e5.

33. Stovitz SD, Banack HR, Kaufman JS. Selection bias can creep into unselected cohorts and produce counterintuitive findings. Int J Obes. 2021;45:276-7. https://doi.org/10.1038/ s41366-020-00720-2.

34. O'Connor PJ, Rush WA, Pronk NP, Cherney LM. Identifying diabetes mellitus or heart disease among health maintenance organization members: sensitivity, specificity, predictive value, and cost of survey and database methods. Am J Manag Care. 1998;4(3):335-42.

35. Donini LM, Pinto A, Giusti AM, Lenzi A, Poggiogalle E. Obesity or BMI paradox? Beneath the tip of the iceberg. Front Nutr. 2020;7:53. https://doi.org/10.3389/fnut.2020.00053.

36. Coutinho T, Goel K, Corrêa de Sá D, Kragelund C, Kanaya AM, Zeller M, et al. Central obesity and survival in subjects with coronary artery disease: a systematic review of the literature and collaborative analysis with individual subject data. J Am Coll Cardiol. (2011) 57:1877-86. https://doi.org/10.1016/j.jacc.2010. 11.058 .

37. Chang AR, Grams ME, Ballew SH, et al. Adiposity and risk of decline in glomerular filtration rate: meta-analysis of individual participant data in a global consortium. BMJ. 2019;364: k5301. https://doi.org/10.1136/bmj.k5301.

Publisher's Note Springer Nature remains neutral with regard to jurisdictional claims in published maps and institutional affiliations. 